\title{
EDUCAÇÃO HISTÓRICA: A CONSTITUIÇÃO DE UM CAMPO DE PESQUISA
}

\author{
Geyso D. Germinari ${ }^{1}$ \\ Universidade Tuiuti do Paraná - UTP
}

\section{RESUMO:}

$\mathrm{O}$ artigo trata da constituição da área de pesquisa denominada Educação Histórica. Esse campo de investigação tem se desenvolvido, principalmente, na Inglaterra, Portugal, Estados Unidos, Canadá e Brasil. Inicialmente, são abordados os primeiros estudos realizados na Inglaterra e Portugal. Em seguida, analisa-se a produção brasileira, com destaque para os estudos realizados pelo grupo de Educação Histórica da Universidade Federal do Paraná. E, por último, apresenta-se um quadro das investigações em Educação Histórica que versam sobre a questão da consciência histórica em jovens na Europa e no Brasil. A investigação utilizou como fonte de pesquisa a análise bibliográfica. A apreciação indica elementos para compreensão dos processos de aprendizagem histórica em crianças e jovens. Esse estudo integra as reflexões da tese de doutorado intitulada: A história da cidade, consciência histórica e identidades de jovens escolarizados, defendida no Programa de Pós-Graduação em Educação, Universidade Federal do Paraná.

Palavras-chave: Educação histórica, aprendizagem histórica, consciência histórica.

\section{HISTORY EDUCATION: THE ESTABLISHMENT OF A RESEARCH FIELD}

\section{ABSTRACT}

The article is about the establishment of a research field called History Education. This research field has had growing importance lately, mainly in England, Portugal United States, Canada and Brazil. Firstly, the first studies conducted in England and Portugal were examined. Then, the Brazilian production was analysed; especially the studies done by the History-Education group from the Universidade Federal do Paraná.( Paraná State Federal University).Finally, it was presented an investigation framework on History Education dealing with the issue of history consciousness among the youth in Europe and Brazil. The investigation used bibliographical analysis as source of research. The assessment of that study provided elements able to aid the understanding of the historylearning process among children, young people and adults. The current study is part of the thoughts found in the doctoral dissertation entitled: : A história da cidade, consciência histórica e identidades de jovens escolarizados, ( the history of town, history consciousness and the identity of schooled youth) presented to the Post- Graduation Programme on education at Paraná State Federal University.

Key Words: History education, history learning, history Consciousness.

\section{INTRODUÇÃO}

O ensino de história é tomado como objeto de pesquisa no Brasil, com maior intensidade, a partir do final da década de 70 e início da década de 80 do século XX. Nesse contexto, marcado pelo processo político de redemocratização que levou ao fim do regime militar (1964-1985), professores de história de escolas públicas e privadas começaram a desenvolver uma série de experiências em suas salas de aula retomando antigos recursos didáticos como os jornais, porém partindo de novas perspectivas teórico-metodológicas. 
Ademais, a partir dos anos 80, a utilização da televisão e dos novos meios de comunicação, como vídeo cassete ampliaram as possibilidades de práticas pedagógicas inovadoras no ensino de história (COSTA; OLIVEIRA (2007), FONSECA, (1995)).

As novas experiências desenvolvidas nas escolas demandaram a criação de espaços nos cursos de graduação voltados à reflexão sobre a prática do ensino de história. Como exemplos, foram criados nas instituições de ensino superior laboratórios de ensino para atender as demandas da área. Portanto, na década de 1980 a formação de professores do ensino de história passa a ser objeto de reflexão e pesquisa nos meios acadêmicos.

A ANPUH espelha o encaminhamento dado pela categoria. A partir de 1977, é posta a discussão e, nos dois Simpósios seguintes (1979 e 1981), consolidaram-se todas as ações necessárias para incluir no quadro de sócios da entidade professores dos outros níveis de ensino, além de professores universitários (COSTA; OLIVEIRA, 2007, p. 148).

A consolidação do campo de pesquisa se deu com a criação de dois eventos fundamentais: o Encontro Nacional Perspectivas do Ensino de História (implementado em 1988 na Faculdade de Educação da Universidade de São Paulo, atualmente na VII realização) e o Encontro Nacional de Pesquisadores de Ensino de História (criado em 1993, atualmente na VIII edição).

Os encontros propiciam o debate, a reflexão e a difusão de conhecimentos sobre as problemáticas do ensino de história nos diferentes níveis e espaços; os processos formativos; à história da disciplina; às políticas públicas; os saberes e práticas de ensino, pesquisa e aprendizagem em História.

Nos últimos anos, tomei contato com um debate que se inicia no Brasil: a Educação Histórica. Tal debate resulta da comunicação entre professores brasileiros e professores de outros paises, principalmente da Inglaterra e Portugal.

\title{
EDUCAÇÃO HISTÓRICA: INVESTIGANDO AS IDEIAS HISTÓRICAS DE CRIANÇAS E JOVENS
}

As investigações em Cognição Histórica, também denominadas pesquisas em Educação Histórica, vêm sendo desenvolvidas com certa intensidade na Inglaterra, Estados Unidos, Canadá, Portugal e Brasil. Segundo Barca (2005, p.15):

\begin{abstract}
Nestes estudos, os investigadores têm centrado a sua atenção nos princípios, tipologias e estratégias de aprendizagem histórica, sob o pressuposto de que a intervenção na qualidade das aprendizagens exige um conhecimento sistemático das idéias históricas dos alunos, por parte de quem ensina (e exige também um conhecimento das idéias históricas destes últimos).
\end{abstract}

As pesquisas que tomam como objeto o ensino-aprendizagem de História filiam-se em linhas teórico-metodológicas diversas e, a partir de fundamentos da Psicologia, Sociologia, História, Antropologia e Didática desenvolvem abordagens diferentes. A perspectiva da Educação Histórica apresenta-se, hoje, com fundamentação científica própria baseada em áreas do conhecimento como a Epistemologia da História, a Metodologia de Investigação das Ciências Sociais e a Historiografia. Assim, a Educação 
Histórica constitui-se como teoria e aplicação à educação de princípios que levam em conta os dados recentes da cognição histórica (BARCA, 2005).

Diferente da pesquisa sobre o desenvolvimento cognitivo da aprendizagem referenciada na Psicologia da Educação, as análises da cognição no viés da Educação Histórica tomam como referência a própria epistemologia da História. Parte-se da premissa de que existe uma cognição própria da História fundamentada na racionalidade histórica que "[...] refere-se a pensamento no trabalho de rememorização da consciência histórica [...]”. (RÜSEN, 1997, p.17). Portanto, a análise da cognição histórica requer um enquadramento teórico especifico circunscrito à natureza do conhecimento histórico, ancorado na epistemologia da História.

As pesquisas em Educação Histórica sustentadas nos pressupostos teóricometodológicos do conhecimento histórico assumem, na atualidade, um conjunto de enfoques que podem ser resumidos em três núcleos: a) análises sobre ideias de segunda ordem; b) análises relativas às ideias substantivas; c) reflexões sobre o uso do saber histórico.

As pesquisas sobre ideias de segunda ordem buscam compreender o pensamento histórico segundo critérios de qualidade, ancorado nos debates contemporâneos sobre a filosofia e teoria da História. Nesse enfoque não interessam as questões relativas à quantidade ou simples correção de informações factuais sobre o passado, mas as questões relacionadas ao raciocínio e a lógica histórica. A análise de ideias substantivas concentrase em reflexões sobre os conceitos históricos, envolve noções gerais (revolução, imigrações...) e noções particulares relativas a contextos específicos no tempo e no espaço (exemplo: histórias nacionais, regionais e locais). Estas análises também utilizam critérios de qualidade destacando valores e motivações associados aos conceitos substantivos da História. As investigações sobre o uso do saber histórico analisam questões relativas ao significado e uso da História na vida cotidiana. Sobre o último enfoque, Barca (2007, p. 27) destaca que:

A reflexão sobre os usos dos significados atribuídos à História (idéias substantivas e de segunda ordem) afigura-se urgente para justificar o papel da História no currículo e contribuir para um ensino que promova uma consciência histórica consentânea com as exigências de desenvolvimento e cidadania na sociedade atual.

A preocupação em conhecer as ideias históricas (substantivas e de segunda ordem) construídas pelos indivíduos e considerá-las como fonte para intervenções significativas no ensino surgiu na Inglaterra. De acordo com Lee (2001, p. 13), pioneiro nos estudos sobre cognição histórica:

nos anos sessenta, surgiu o receio de que os alunos deixassem de estudar História, o que de facto quase aconteceu. Existia um currículo descentralizado em Inglaterra e poucos alunos escolhiam a disciplina de História. Esta assemelhava-se a um conjunto de histórias e as crianças, quando as conheciam, não gostavam delas. Gostavam mais das histórias da TV, dos livros, etc. Em vez de aprenderem conhecimentos substantivos sobre o passado, os alunos aprendiam "estórias".

A situação de descrédito pela qual passava a disciplina de História na Inglaterra começou a mudar com o projeto 13-16 (coordenado na última fase por Denis Shemilt), cujo principal objetivo era abordar o Ensino de História em termos históricos. Dito de 
outra forma, o projeto pautava-se na ideia de que aprender História era aprender a pensar o passado historicamente. Este projeto, organizado para crianças de 13 aos 16 anos, atingiu toda a Inglaterra envolvendo mais de um terço das escolas, modificando a concepção da disciplina.

Lee (2001, p. 14) destaca que:

Uma das razões pelas quais as pessoas mudaram foi constatar que anteriormente, as crianças encaravam a História como maçadora e inútil e os pais também a achavam assim; com o Projecto, as crianças passaram a olhar para a História como uma disciplina séria. Era necessário haver algo que as crianças aprendessem progressivamente, que se operassem mudanças de idéias e que elas conseguissem perceber essas mudanças. De facto, as crianças relacionavam melhor suas idéias em História.

No contexto, o projeto sugeriu novas questões sobre o ensino de História tais como: "Que idéias é que as crianças traziam para a disciplina de História? Quais os conceitos, quais as imagens que História fornecia às crianças?” (LEE, 2001, p.14). Esses questionamentos orientaram as primeiras investigações sobre Cognição Histórica de alunos na Inglaterra.

O estudo de Dickinson e Lee realizado em 1978 com alunos de 12 a 18 anos, considerado um marco das pesquisas em Cognição Histórica, imprimiu um novo olhar sobre a questão da aprendizagem histórica. Este estudo questionou as pesquisas anteriores sobre essa aprendizagem baseadas em lógicas não históricas, como a noção piagetiana de invariância dos estágios de desenvolvimento humano. Dickinson e Lee (1978) demonstraram que algumas crianças de 8 a 11 anos apresentavam desempenho adequado em tarefas idênticas aplicadas em jovens de 12 a 14 anos, constatação que refuta a teoria da invariância dos estágios de desenvolvimento de Jean Piaget.

A partir desse estudo, Lee desenvolveu um modelo de progressão das ideias baseado na natureza da explicação histórica que foi aprofundado por Dickinson e Lee (1984) em outro estudo realizado com alunos de 8 a 18 anos, ocasião em que abordou as noções de empatia e imaginação histórica fundamentais à explicação histórica.

Ashby e Lee (1987) desenvolveram novos estudos sobre a compreensão histórica, com alunos de 11 aos 18 anos criando um modelo de progressão mais sistematizado das ideias sobre empatia e compreensão histórica. As ideias dos alunos foram categorizadas da seguinte forma:

1) O "passado opaco", quando as acções e instituições do passado parecem ininteligíveis;

2) "Estereótipos generalizados", quando as acções e instituições do passado são compreendidas por referência a uma descrição convencional de intenções, situações e valores;

3) "Empatia com a História a partir do quotidiano", quando as acções e instituições do passado são compreendidas por referência ao tempo actual, sem distinção entre o passado e o presente;

4) "Empatia histórica restrita", quando as acções e instituições do passado são compreendidas a partir da evidência sobre a situação histórica específica;

5) "Empatia histórica contextualizada", quando as acções e instituições do passado são compreendidas a partir da evidência sobre a situação específica e explicadas num conjunto mais vasto. (ASHBY; LEE (1987) apud BARCA, 2005, p. 17) 
A categorização proposta por Ashby e Lee (1987) representa uma progressão lógica hierárquica dos conceitos de compreensão e empatia histórica, no qual os níveis inferiores são substituídos por níveis superiores. Esses investigadores aprofundaram os seus estudos no projeto CHATA (Conceitos de História e Abordagens de Ensino), destinado a explorar a compreensão histórica dos alunos. O projeto utilizou uma amostragem de 320 alunos, entre 6 e 14 anos de idade, de 3 escolas primárias e 6 escolas secundárias. Os alunos responderam perguntas sobre compreensão de causalidades, empatia, objetividade da pesquisa histórica, evidência e narrativa.

De acordo com Lee (2001, p. 16):

Uma das tarefas consistiu na apresentação de duas histórias diferentes sobre a ocupação romana das ilhas Britânicas, em bandas desenhadas. Essas bandas desenhadas continham textos contraditórios: a primeira história referia os benefícios dos britânicos com a chegada dos romanos, pois até aí viviam em casas de madeira: a segunda história referia a vida agradável que os britânicos tinham antes da chegada dos romanos, e que após a invasão os britânicos passaram a imitar os romanos. Em suma, a primeira história reportava o bem material de que britânicos beneficiaram, mas que acabou quando os romanos desapareceram. A segunda história era temporalmente mais longa, falava da cultura e da sua permanência.

A partir das histórias foi colocada a seguinte questão às crianças: como podiam existir histórias diferentes sobre um mesmo fato (ocupação romana das ilhas britânicas). Os resultados da investigação evidenciaram que as crianças mais novas compreendiam que as histórias eram idênticas, identificaram diferenças apenas na forma da escrita. "Portanto, para os mais novos, a diferença está na forma como se conta a história. Não percebem como se pode contar a história sob perspectivas diferentes". (LEE, 2001, p. 18).

Alguns alunos mais velhos pensaram que as diferenças decorrem do conhecimento que o autor do texto tem do assunto. Apesar dos mais velhos entenderem que as diferenças fossem um problema do autor, um pequeno grupo entre os 7 e 9 anos expressou a ideia de que as diferenças eram relativas à natureza da História. Diante dos resultados, Lee (2001, p. 20) afirma que:

As crianças de 7 e 8 anos pensam de forma diferente das de 14 anos e vice-versa. Mas há alunos de 7 anos que já pensam como os de 14 anos. Há crianças que já sabem que as histórias não são cópias do passado, elas são construídas.

Essa análise indica que a aprendizagem ocorre em termos de uma progressão. No modelo proposto por Lee (2001), a progressão da aprendizagem histórica deveria ocorrer pela compreensão sistemática de conceitos substantivos (agricultor, impostos, datas, eventos), e também pela compreensão de conceitos de segunda ordem, esses relacionados à natureza do conhecimento histórico, como narrativa, relato, explicação histórica, consciência histórica. Segundo Lee (2001, p. 15), “é importante investigar as idéias das crianças sobre estes conceitos, pois se tiverem idéias erradas acerca da natureza da História elas manter-se-ão se nada fizer para as contrariar”. Schmidt e Garcia (2006a, p. 9) corroboram a ideia de Peter Lee: 
[...] a Educação histórica tem seus fundamentos pautados em indagações como as que buscam entender os sentidos que os jovens, as crianças e os professores atribuem a determinados conceitos históricos - como revolução francesa, renascimento, reforma protestante - chamados "conceitos substantivos", bem como os chamados de "segunda ordem" tais como narrativa, explicação ou evidência histórica.

Nessa perspectiva, o progresso na aprendizagem histórica passa pela reflexão de como aliar a compreensão histórica (conceitos de segunda ordem) ao saber substantivo do passado. Para que essa relação aconteça, segundo Lee (2006), é necessária uma noção aplicável de literacia histórica. Esse conceito refere-se ao conjunto de competências de interpretação e compreensão do passado que permite ler historicamente o mundo. Nesse sentido, a competência histórica envolve a apreensão de elementos epistemológicos do conhecimento histórico.

Diante dessa exigência, um programa de Educação Histórica fundamentado nos debates contemporâneos da Teoria e da Filosofia da História envolve a apreensão de alguns saberes:

a) Saber ler diferentes fontes históricas, com suportes diversos (fotografia, pinturas, documentos escritos, depoimentos orais, cultura material);

b) Saber selecionar fontes para confirmação ou refutação de hipóteses;

c) Saber entender o nós (identidade) e os outros (alteridade) em diferentes tempos e espaços;

d) Saber levantar novas hipóteses de investigação.

O desenvolvimento gradativo de cada saber relacionado constitui a essência da progressão da aprendizagem histórica em todos os níveis de ensino. As pesquisas em Educação Histórica realizadas em vários países apresentam algumas convergências:

a) A aprendizagem ocorre em contextos concretos;

b) As crianças e os jovens usam suas experiências para dar sentido ao passado, o qual nem sempre se ajusta as suas ideias prévias;

c) Vários fatores influenciam a cognição histórica, tais como as vivências prévias dos sujeitos, a natureza específica do conhecimento, os tipos das tarefas ofertadas e as aptidões individuais. Estes são elementos fundamentais para progressão do conhecimento;

d) As ideias históricas de crianças e jovens apresentam uma progressão lógica, mas não invariante, cada sujeito pode oscilar entre níveis mais ou menos elaborados conforme a situação. A progressão de ideias por idade é tendencial, mas não determinante.

\section{EDUCAÇÃO HISTÓRICA NO BRASIL}

No Brasil, a presença da Educação Histórica foi evidenciada pelo trabalho de Evangelista e Triches (2006). As autoras sistematizaram as informações sobre grupos de pesquisa em Ensino de História, Didática da História e Educação Histórica, cadastrados no Conselho Nacional de Desenvolvimento Científico e Tecnológico (CNPQ), entre 2000 e 2005. Entre os resultados obtidos, constataram a presença de grupos de pesquisa (GPs) e linhas de pesquisa (LPs) em Educação Histórica a partir do ano de 2005. 
Considerando que no Brasil existem poucos estudos sistematizados sobre as pesquisas em Ensino de História realizadas ou em andamento, Schmidt (2005), a partir da sistematização de Laville (1999), propõe uma forma de aglutinação das pesquisas em dois grandes eixos: 1) Pesquisas que estudam a aprendizagem histórica dos alunos; 2) Pesquisas sobre a função social da História. De acordo com Schmidt (2005) estas pesquisas estão em fase de consolidação, por isso apresento apenas as investigações realizadas pelo grupo de Educação Histórica da UFPR. Conforme Schmidt e Garcia (2006b, p. 27):

neste momento, o saldo da trajetória das investigações em Educação Histórica, assumidos pelo Laboratório de Pesquisa em Educação Histórica, do Programa de Pós-Graduação em Educação da UFPR, já apresenta uma visibilidade em trabalhos que foram e estão sendo desenvolvidos, seja como sistematizações de experiências, de reflexões ou como resultado de investigações cientificamente mais elaboradas em diferentes âmbitos.

No âmbito dos projetos de extensão, o projeto "Recriando a História", em curso desde 1995, tem como proposta a formação continuada de professores da escola fundamental. Nesse âmbito, têm sido publicados artigos pelos professores e alunos da UFPR sobre o projeto apresentados em encontros nacionais e internacionais. Essa produção traz subsídios significativos ao campo da Educação Histórica, particularmente os artigos de Schmidt e Garcia, que trazem contribuições ao estudo da consciência histórica.

No âmbito da Pós-Graduação, a

[...] criação dentro da Linha de Pesquisa Cultura, Escola e Ensino, do grupo cadastrado no Conselho Nacional de Desenvolvimento Científico e Tecnológico $(\mathrm{CNPq})$, com o nome de Cultura, Saberes e Práticas Escolares e Educação Histórica, e também do Laboratório de Pesquisa em Educação Histórica, grupo agrega professores e alunos cujas atividades estão voltadas ao Ensino de História e, mais particularmente, à Educação Histórica [...]. (SCHMIDT; GARCIA, 2006b, p. 28)

Entre os conceitos utilizados pelo grupo de Educação Histórica da UFPR, o de consciência histórica assume posição central. No entanto, os primeiros estudos sobre consciência histórica de jovens foram realizados no continente europeu.

\section{PESQUISAS SOBRE CONSCIÊNCIA HISTÓRICA DE JOVENS}

As investigações que tratam o tema da consciência histórica vêm sendo desenvolvidas a partir de diferentes perspectivas. Nesse sentido, apresentam-se como possibilidades as pesquisas comparativas interculturais baseadas na aplicação de questionários fechados e/ou abertos (ANGVIK; BORRIES, 1997), o inquérito do projeto Youth and History e a análise de narrativas históricas e de outros materiais de estudantes. Conforme afirma Rüsen, (2001), as abordagens teórico-metodológicas da consciência histórica precisam levar em conta que esta consciência se expressa em narrativas estruturadas do passado, cuja coleta e análise das ideias dos sujeitos investigados são a base para o estudo desse tema, qualquer que seja o método empregado. 
As pesquisas sobre consciência histórica de jovens tiveram origem na Alemanha, no contexto da unificação entre a República Democrática Alemã (RDA) e a República Federal da Alemanha (RFA). No início da década de 1990, mudanças estruturais transformaram o cenário político internacional levando à reorganização da economia mundial. Os principais acontecimentos foram o fim da guerra fria com o colapso do bloco socialista e consequente desintegração da URSS e a unificação da Alemanha simbolizada pela queda do Muro de Berlim.

A difusão generalizada do termo "reunificação", para representar a união da Alemanha, trazia a ideia da incorporação da RDA à RFA. Em outras palavras, o Estado unificado deveria seguir o modelo político e econômico capitalista da Alemanha Ocidental (RFA). Com o desenvolvimento da "reunificação" chegou-se à conclusão na Alemanha Ocidental que a história da Alemanha Oriental poderia desaparecer.

De acordo com Jung e Staher (1998, p. 133):

O não reconhecimento da história da Alemanha oriental como parte da história global alemã desde 1945/49, junto com a experiência da supremacia política e econômica da RFA, produziu o fato de que desde 1994 começou a parecer uma nova identidade germana-oriental. Lentamente se irá reconhecendo que a reconstrução da história da RDA como parte da história da Alemanha em seu conjunto constituía um requisito essencial para o futuro auto-determinado da Alemanha unificada.

Na Alemanha, na década de 1990, as condições da aprendizagem da história foram profundamente influenciadas pelos problemas gerados pela reunificação. As novas condições administrativas que passaram a reger o ensino de História nas escolas evidenciavam a existência de um esforço de instrumentalizar o ensino sob a tutela ideológica da Alemanha Ocidental.

As concepções de ensino de História tinham como base conceitos didáticos diferentes, os quais geravam práticas de ensino e pesquisa diferentes. Diante da realidade da unificação, professores e pesquisadores dos dois Estados tiveram que encontrar um modo de ensino e aprendizagem de História adequada à nova situação política e social.

$\mathrm{Na}$ Alemanha ocidental o ensino de História foi marcado pelo compromisso com a investigação teórica sobre os efeitos sociais da história ensinada em uma sociedade plural, tanto na política como na ciência. Por outro lado, a Alemanha oriental priorizou os aspectos metodológicos do ensino de História determinados pelo Estado. "Dado que na RDA a doutrina estatal marxista-leninista não permitia controvérsias científico-históricas tampouco havia posições divergentes acerca da didática da história, como na RFA". (JUNG; STAHER, 1998, p. 135).

Nesse contexto, a formação dos professores de História também foi diferente. $\mathrm{Na}$ Alemanha oriental a formação era essencialmente voltada à pedagogia, com foco especial na parte instrumental do ensino. Os chamados "metódicos da história" discutiam questões de métodos de ensino, psicologia da aprendizagem e desenvolvimento das classes sociais. Além disso, mantinham permanente relação com as escolas, uma vez que também foram responsáveis pela formação continuada dos professores. A Alemanha ocidental privilegiou a formação histórica dos seus professores.

De acordo com Jung e Staher (1998, p. 135):

Por conseguinte, se desenvolveu na RDA um entendimento teoricista da metodologia da história. Estes pontos fortes da metodologia da história na 
RDA foram ignorados no ocidente. Em vez disso se incidiu na função de apoio ao sistema uma consistente formação político-ideológica dos escolares. Assim foram demitidos todos os professores integrantes da metodologia da história.

Nessa conjuntura, havia o entendimento de que o ensino de História praticado na antiga RDA se transformaria profundamente de acordo com as normas didáticas que imperavam na RFA.

Depois da unificação foram desenvolvidos cursos de preparação dos professores. Neles trabalhava-se a visão ocidental sobre a história da RDA pós 1945 com as correspondentes consequências curriculares para a aprendizagem histórica e o método de trabalho em sala de aula. Contudo, nem os professores e nem os metódicos da RDA abandonaram seu campo de ação sem propor iniciativas próprias. Como afirmam Jung e Staher (1998, p. 137):

Já em junho de 1990, alguns meses antes da unificação, os "metódicos da história" decidiram em seu último congresso rebatizar-se como didatas da história. Assim, documentaram a sua vontade de reorientar-se para a didática da história da Alemanha Ocidental, que na época era fortemente tendenciosa e idealizada.

A aproximação entre os didatas da história das antigas RDA e RFA caracterizou-se pela aceitação generalizada da categoria de "consciência histórica" em detrimento do conceito de identidade nacional. Conforme Jung e Staher (1998, p. 138-139),

O curto debate sobre a validade da "emancipação" ou seja, sobre o alcance da "identidade nacional" como idéia-guia da aprendizagem histórica diminuiu sem grandes controvérsias graças a aceitação da categoria relativamente indeterminada de "consciência histórica". Além de evitar conflitos se obteve, um benefício: a didática da história deve integrar a função, a morfologia, a gênesis, assim como a construção e a remodelação das consciências históricas que se pode encontrar na sociedade. Através do ensino, os escolares devem formar uma consciência história na qual se relacionem passado, presente e futuro, de tal modo que pode obter-se uma orientação presente e futura. A categoria de consciência histórica é, por isto, meramente formal, o que explica sua capacidade de consenso.

A categoria "consciência histórica" foi incorporada com o objetivo principal de formação histórica dos estudantes alemães. Esta categoria foi referenciada principalmente nos estudos do filósofo da história alemão Jörn Rüsen. Para este autor, a consciência histórica é a consciência da relação estrutural entre passado, presente e futuro. A formação dessa consciência não se produz unicamente na escola, mas também em outros espaços da sociedade. Nessa perspectiva, a Didática da História como área específica de reflexão e intervenção sobre o ensino-aprendizagem expandiu-se para novos lugares, como os museus, arquivos, mídias (literatura, televisão, cinema), viagens, meio familiar, âmbitos tradicionalmente negligenciados como elementos didáticos.

Além do trabalho de delinear a definição da categoria consciência histórica como elemento principal da formação histórica, também foram apresentados estudos empíricos com alunos e professores. 
Os resultados de uma das investigações desenvolvidas com alunos da Alemanha (oriental e ocidental) e da Europa do leste e oeste surpreenderam os investigadores quando concluíram que não havia grandes diferenças entre a consciência histórica dos alunos orientais e ocidentais. Sobre esse estudo, Jung e Staher (1998, p. 140) dizem que:

Pelo que se refere à estrutura da consciência histórica, que aqui há sido novamente dimensionada (informação técnica, capacidade de crítica, orientação sobre os valores básicos) se evidenciou que os alunos medem majoritariamente os personagens e os acontecimentos históricos segundo uma escala de valores atual, e que a capacidade de compreensão do foráneo esta muito debilmente desenvolvido.

Outra investigação realizada com mais de 6000 estudantes dos Estados da Alemanha ocidental e de cinco Estados da Alemanha oriental e com professores de história demonstrou resultados semelhantes. Desses resultados, segundo Jung e Staher, o investigador Bodo Von Borries extraiu algumas consequências para o ensino de história: “a) Elementarización de la gradación de la enseñanza; b) Intensificación de los métodos; c) Fomento de la comprensión hacia lo extranjero; d) Estimulación de la reflexión" (VON BORRIES apud JUNG; STAHER, 1998, p. 140).

Depois dos primeiros estudos, outras pesquisas foram desenvolvidas em vários países também baseadas no conceito de consciência histórica delineado por Rüsen. Segundo Schmidt (2005, p. 118):

Nestas pesquisas, não se trata de analisar programas de manuais, para se presumir os efeitos no ensino de História, mas de pesquisar estes efeitos nos sujeitos que foram objeto de ensino. Também não têm como fonte de pesquisa apenas os saberes escolares, mas outras fontes como a família, os mídia, as circunstâncias da vida das pessoas, as quais são consideradas igualmente importantes para aprendizagem histórica.

A maior pesquisa deste gênero foi realizada no continente europeu no final da década de 1990. Um grupo de pesquisadores de vários países sob coordenação do norueguês Magne Angvik e do alemão Bodo von Borries estruturou o projeto Youth and History (1997). A referência principal do projeto foram as investigações interculturais de Borries desenvolvidas no âmbito da Didática da História e os estudos teóricos de Rüsen sobre a consciência histórica.

A pesquisa organizada no formato survey tinha como objetivo responder questões sobre as características, qualidade e resultados do ensino de História e, particularmente, sobre a configuração geral da consciência histórica dos jovens europeus.

A investigação buscou identificar e avaliar o conceito de consciência histórica na perspectiva de jovens de 15 anos e seus professores em 25 países europeus, mais Israel, Palestina e Turquia, os quais responderam um questionário, com perguntas sobre conteúdos, métodos de ensino e concepções de História e cidadania. O levantamento de dados foi de amplo alcance e contou com 32.000 respondentes. Em cada país foram aplicados, em média, 800 a 1200 questionários nas salas de aula durante o horário da aula de história.

O questionário abordou vários temas, além de informações para contextualizar cada indivíduo. Os estudantes responderam questões sobre a concepção e a importância da História; confiança em fontes de conhecimento histórico; cotidiano das aulas de história; conhecimentos cronológicos de fatos históricos; interesses por gêneros e períodos 
históricos; interesse pela história por área geográfica; conceito de mudança histórica; representações atribuídas a personagens e períodos históricos; concepção de temporalidade histórica; concepções de passado e expectativas de futuro pessoal e nacional; preservação do patrimônio; fatores da divisão do país em classes; perguntas sobre tomada de decisão pessoal em se vivendo situações passadas e futuras (como o pagamento de indenização pela colonização das nações africanas, por exemplo); concepções de nação e Estado, nacionalidade e soberania sobre um território e posição política sobre questões de urgência nos países ou na Europa em geral (como por exemplo, energia nuclear e armamento bélico). Os temas desdobraram-se em perguntas sistematizadas como afirmações que foram respondidas pelos jovens ao escolherem um dos itens colocados em uma escala de valoração iniciada com "discordo totalmente" até "concordo totalmente", passando por "discordo", "sem opinião" e "concordo".

Os professores responderam perguntas relacionadas à contextualização do indivíduo nos países, experiência de ensino em anos, formação acadêmica, estudos desenvolvidos no campo da História, informações sobre sua prática de ensino de História, particularidades do currículo de História, avaliação da capacidade cognitiva dos alunos, significado da religião para vida do professor, interesse por política para o cotidiano do professor, conceitos históricos (nação, democracia, Europa, integração européia) trabalhados em sala, questões de método de ensino-aprendizagem, objetivos do ensino de História, fatores de mudança históricas consideradas mais relevantes e projeções de futuro quanto a fatores de mudança histórica.

Segundo Barca (2007, p. 117), os pesquisadores Angvik e Borries (1997):

reconheceram que as idéias manifestadas pelos jovens de 15 anos em diversos países europeus acerca do passado, presente e futuro são o espelho da mentalidade dos respectivos povos: se os jovens de países mais industrializados se mostram mais críticos face ao passado, os de países com economias mais tradicionais assumem uma postura de maior aceitação e até de entusiasmo face ao estudo da História.

Esta constatação remete à ideia de que a consciência histórica é culturalmente variável. Em outras palavras, mudando o contexto cultural mudam as relações entre as interpretações do passado, percepções do presente e expectativas do futuro. Na perspectiva de Angvik e Borries (1997), é plausível pensar a existência de uma intricada relação entre cultura e consciência histórica, porém, tal relação está longe de ser mapeada em todos os seus detalhes. Pais (1999, p. 3) corrobora com Angvik e Borries. Em suas palavras:

Embora a consciência histórica seja discursivamente representada, cientificamente interpretada e teoricamente explicada, e apesar de genérica ou vagamente se sustentar que ela depende da "cultura", não há referências empíricas fidedignas sobre a formação da consciência histórica entre as jovens gerações.

As discussões de Rüsen (2001) sobre a relação da consciência histórica e a vida prática contribuem na problematização da questão colocada por Angvik e Borries (1997) e Pais (1999). A partir do pensamento de Rüsen (2001), pode-se afirmar que a realidade do jovem se expressa na consciência histórica, e que, de alguma maneira, os elementos que constituem a vida do jovem estão presentes na sua consciência histórica. Nessa direção, conhecer as estruturas identidárias presentes na cultura juvenil pode revelar aspectos da relação entre cultura e consciência histórica. 
A participação portuguesa no projeto Youth and História, coordenada por Pais (1999), contou com a aplicação do inquérito principal numa amostra nacional de alunos do $9^{\circ}$ ano, cerca de 1200 jovens, durante as aulas da disciplina de História. Como nos outros países também foram inquiridos os respectivos professores de História. A investigação ainda recorreu a outros instrumentos de pesquisa. Segundo Pais (1999, p. 9):

Paralelamente à aplicação deste instrumento de inquirição extensiva - o questionário fechado - fiz uso de metodologias qualitativas ou indiciárias, envolvendo, principalmente, entrevistas aprofundadas a professores e estudantes de História. Nalguns casos, fiz reuniões informais de grupo de modo a produzir uma situação de comunicação que favorecesse a captação, entre alunos e professores, de representações simbólicas sobre a História e o seu ensino. Desejava também ver como a consciência histórica - sendo uma forma de consciência social - acabaria por emergir num contexto grupal, propiciador do surgimento de categorias e interpretações geradas numa base hermenêutica e dialógica, ainda que sob forma discursiva.

Os resultados da investigação portuguesa foram sistematizados no livro Consciência histórica e identidade: os jovens portugueses num contexto europeu, de autoria de José Machado Pais (1999). A obra comporta três partes principais. A primeira destinada à aprendizagem da História e suas imagens começa aferindo sobre algumas representações dos jovens europeus, em particular dos jovens portugueses, sobre o significado da história e seus objetivos. Na parte dois, consagrada à temporalidade e à mudança histórica, os jovens são confrontados com várias representações do tempo e também com fatores de mudanças dos tempos presente e do futuro próximo. A terceira parte trata das atitudes e representações sociais que se expressam na consciência histórica dos jovens, onde foram analisadas opiniões dos jovens sobre juízos históricos relacionados às desigualdades sociais; à desvalorização do patrimônio histórico; aos conflitos políticos (direito dos imigrantes, por exemplo); às atitudes políticas que se prendem aos conceitos de nação/Estado, à Europa/integração europeia e democracia; às atitudes sobre a vida presente e expectativas de futuro.

A obra de Pais (1999) trata especialmente da relação entre consciência histórica e identidade, questão expressada no título e retomada em vários momentos do texto. Como este autor afirma:

Sem consciência histórica sobre o nosso passado (e antepassados...) não perceberíamos quem somos. Esta dimensão identidária - quem somos? emerge no terreno de memórias históricas partilhadas. Por isso, o sentimento de identidade - entendida no sentido de imagem de si, para si e para os outros - aparece associada à consciência histórica, forma de nos sentirmos em outros que nos são próximos, outros que antecipam nossa existência que, por sua vez, antecipará a de outros. Ao assegurar um sentimento de continuidade no tempo e na memória (e na memória do tempo), a consciência histórica contribui, deste modo, para afirmação da identidade individual e colectiva.

É sabido que a História não tem um sentido independente daquele que os indivíduos lhe dão. Por isso, o estudo das formas de consciência histórica é uma forma de conhecimento que nos permite descobrir como os indivíduos vivem com os 'fantasmas' do passado e, simultaneamente, os utilizam como forma de conhecimento. (PAIS, 1999, p.1) 
Portanto, as identidades individuais e coletivas construídas pelos jovens estariam intrinsecamente associadas a sua consciência histórica. Segundo Pais (1999, p. 2), "a consciência histórica é uma construção simbólica, do mesmo modo que a identidade comporta também um processo de apropriação simbólica do real". Nessa perspectiva, torna-se possível pela investigação científica da consciência histórica produzir conhecimento útil sobre a vida dos jovens, pois a vida se expressa de alguma maneira na consciência histórica e nela é possível apreender a vida dos seres humanos (RÜSEN, 2001). Pais (1999) buscou compreender a relação entre as dimensões identitárias individuais e coletivas da vida dos jovens que se expressam em sua consciência histórica.

O problema colocado por Pais (1999) vem acompanhado da hipótese de que a consciência histórica dos jovens tem uma forma específica de "inscrição geracional". Em sua perspectiva, as afinidades e sentimentos que ligam os jovens a uma geração possibilitam a participação num destino comum: um passado lembrado, um presente vivido, um futuro esperado. Em outras palavras, permite uma determinada consciência histórica. Para este autor, a consciência histórica dos jovens europeus e portugueses seria, muito provavelmente, constituída pela identidade geracional.

Tendo como referência os resultados aferidos no projeto Youth and History, as pesquisas brasileiras têm investigado elementos constitutivos da consciência histórica de jovens em diferentes níveis de ensino, seja na perspectiva da contribuição do material didático (MEDEIROS, 2005) ou da relação dos jovens brasileiros com o conhecimento histórico escolar (SCHMIDT, 2002).

A pesquisa de Schmidt (2002) insere-se num conjunto de investigações que estudam a identidade dos jovens que frequentam o ensino médio e a suas relações com as formas do conhecimento histórico. Segundo Schmidt (2002, p. 184-185), um dos objetivos do seu estudo "foi procurar levantar indícios sobre a relação dos jovens com o conhecimento histórico, interrogando-os sobre as relações entre estes conhecimentos e sua própria vida". Para compreender as articulações entre o processo de construção do conhecimento histórico e a vida dos jovens, a autora partiu da conceituação históricosociológica da juventude, contextualizada numa determinada sociedade urbano-industrial.

A investigação acompanhou os alunos no seu cotidiano escolar, por meio de observações e elaboração de memorandos. Também contou com entrevistas individuais e coletivas, juntamente com a aplicação de questionário elaborado segundo modelo aplicado em jovens alunos de escolas europeias (Youth and History). O campo de pesquisa foi delimitado em duas escolas da cidade de Curitiba, capital do Estado do Paraná, integrantes do sistema de ensino público estadual.

A escola S, localizada em bairro de periferia, tinha um total de 1.500 alunos, nos terceiros e quatro ciclos do ensino fundamental e ensino médio. Nessa escola, de acordo com Schmidt (2002, p. 187):

A primeira parte da pesquisa foi realizada durante um ano, em 1999, com uma amostra de 21 alunos, sendo 11 da $1^{a}$ série e 10 da $2^{\circ}$ série. Foram observadas e entrevistas nove meninas entre 15 e 16 anos, 12 meninos entre 15 e 18 anos e dois professores, todos do turno da manhã. No primeiro semestre de 2000 foram distribuídos 80 questionários aos alunos interessados, dos quais retornaram e foram analisados 62 questionários dos alunos da $1^{\mathrm{a}} \mathrm{e} 2^{\mathrm{a}}$ séries. 
A escola E, situada no centro da cidade, oferece desde 1992 apenas o ensino médio. Na época da pesquisa contava com aproximadamente 3000 alunos. De acordo com Schmidt (2002, p. 187):

A primeira parte da pesquisa na Escola $\mathrm{E}$ também foi realizada durante o ano de 1999, com 35 alunos, todos da primeira série, sendo que 20 eram do sexo masculino e 15 do feminino, além de observados e entrevistados três professores, todos do turno da tarde. No ano de 2000 foram distribuídos 160 questionários dos quais retornaram e foram analisados 117 dos alunos da $1^{\mathrm{a}}$ e $2^{\mathrm{a}}$ séries.

Os resultados parciais indicam, de modo geral, a contradição entre os interesses e necessidades dos jovens alunos e a prática do ensino de História. A comparação entre a pesquisa realizada com jovens brasileiros e as pesquisas desenvolvidas com jovens europeus permite concluir que há contradições entre as expectativas de vida dos jovens brasileiros e europeus e os conteúdos de História ensinados na escola.

Segundo Schmidt (2002, p. 195):

Note-se a ambigüidade presente na fala dos jovens alunos, bem como a opção ou escolha dos conteúdos históricos que, várias vezes, oscila. De um lado, há preocupação pela busca da construção de uma identidade pessoal, orgânica, profissional, social, identificada com a própria vida; de outra, a presença de uma identidade legitimada pela própria sociedade, como a escola e os meios de comunicação, cujo vetor principal seria o conteúdo tradicional da história política.

De acordo com a autora, a relação dos jovens brasileiros com o conhecimento histórico escolar é matizada, por um lado, pela sua identidade pessoal identificada com suas expectativas profissionais e de futuro, e, por outro lado, por uma identidade histórica legitimada pela escola, a mídia e a sociedade, identificada com o conteúdo tradicional da História política. Pode-se dizer que existe na escola um choque de interesses. Essa situação fica evidente no depoimento de uma aluna da Escola S, coletado por Schmidt (2002, p. 194):

Bom, eu acho que não tem nada a ver isso que a gente tá estudando, não sei no que vai levar, não sei o que a gente vai levar pra vida, assim..., pro futuro. Acho que é mais pra quem vai estudar História, pra quem quer dar aula disso... Pro que eu penso em fazer, não tem nada a ver com História, porque eu penso em fazer Odontologia, então fica meio desligado, né? Mas sim... é importante... mas sim... tem certas coisas que não têm um porquê, que nem o Império Brasileiro, lá de 1.800 e bolinha... não tem nada a ver... Agora, tem coisas que são legais, que são importantes você saber, que nem o descobrimento do Brasil, acho bem importante!

A partir da constatação de que os jovens se relacionam com o conhecimento histórico escolar mediante seus interesses e desejos, Schmidt (2002) procurou explicitar a articulação dessa relação com a formação da consciência histórica dos jovens. Essa discussão tomou como referências os estudos de Tutiaux e Mousseau (1998), Pais (1999), especialmente o modelo de questionário aplicado a jovens europeus, e Rüsen (1992).

Nos últimos anos têm aumentado as pesquisas sobre consciência histórica de jovens em diversos países. As pesquisas de vários autores têm analisado os sentidos das 
mensagens nucleares que os jovens apresentam, principalmente, referentes aos seus países. Essas análises estão presentes em: Seixas e Clark (2004), Letourneau e Moisan (2004), no Canadá; Wertsch (2004), na Rússia; Barton e McCully (2005) na Irlanda do Norte e Waldron e Pike (2005) na República da Irlanda ${ }^{2}$. Essas pesquisas analisaram narrativas de jovens de 15 anos sobre seus países e perceberam a permanência de determinados tipos de identidade nacional, apesar de críticas anunciarem o fim deste tipo de identidade. Outras pesquisas procuram amarrar o conhecimento de uma história substantiva em ideias de segunda ordem, como é caso das pesquisas de K. Barton (2001), P. Seixas (2004) e P. Lee $(2002)^{3}$.

\section{CONSIDERAÇÕES FINAIS}

De acordo com Barca (2009, p. 53):

Na pesquisa recente em Educação Histórica a busca de elementos para a compreensão da consciência histórica, em especial a dos jovens, constitui-se como um dos objetos centrais de pesquisa com a intenção de reunir dados empíricos que possibilitem um melhor entendimento acerca das idéias e usos de história, no quotidiano das pessoas mais ou menos letradas historicamente.

Estas investigações tiveram origem na Alemanha. A utilização do conceito de consciência histórica no ensino de História emergiu das discussões entre especialistas em didática da antiga RDA e RFA, na década de 1980. Nas palavras de Jung e Staher (1998, p. 138):

os anos 80 se caracterizaram por uma aproximação entre didatas da história mais progressistas e os mais conservadores. Esta aproximação cristalizou em uma aceitação generalizada da categoria de "consciência histórica" como categoria central da didática da história.

Depois foram desenvolvidas investigações em vários países, tendo como referência principal o conceito de consciência histórica delineado pelo historiador Rüsen. A maior pesquisa nesta área foi desenvolvida por Magne Angvik e Bodo von Borries (1997). "Trata-se de uma enquête aplicada em 25 países europeus, mais a Palestina, Israel e Turquia, com um conjunto de 32 mil jovens de 15 anos, para conhecer, sob orientação de um questionário, o conteúdo da sua consciência histórica". (SCHMIDT, 2005, p. 118). Essa pesquisa definiu a consciência histórica como uma operação mental complexa que estabelece conexão entre a interpretação do passado, a compreensão do presente e a expectativa do futuro. Também concluiu que as ideias manifestadas pelos jovens, dos diversos países que participaram da investigação, sobre o passado, presente e futuro, refletem a mentalidade dos respectivos povos. Portanto, o estado da arte destas pesquisas permitiu considerar que a consciência histórica e, portanto, a identidade dos jovens está intimamente relacionada ao contexto cultural e as dimensões individuais e coletivas das experiências com o passado.

Visto que o quadro conceitual proposto por Rüsen (2001) tem orientado as pesquisas sobre consciência histórica de jovens, foi aprofundada a análise da relação consciência histórica e identidade a partir dos estudos deste autor. As contribuições para a discussão epistemológica acerca das relações da História com a vida prática têm 
possibilitado identificar alguns caminhos de análise da consciência histórica de jovens. De acordo com Rüsen (2001), por seu papel em nos orientar no tempo, a consciência histórica tem duas funções essenciais: orientação temporal da vida prática externa e interna.

A competência interna de orientar a vida prática denomina-se identidade histórica. A identidade histórica fornece à vida um sentido temporal de continuidade entre o passado, o presente e o futuro. Esse trabalho da consciência histórica realiza-se nas práticas de narração histórica.

Ademais, Rüsen (2001) afirma que o arranjo das três dimensões temporais (passado, presente, futuro), pela narrativa histórica, assume formas diferentes conforme o quadro de referências de orientação cultural da existência humana, que incluem diferentes dimensões identidárias construídas ao longo da vida.

\section{REFERÊNCIAS}

ANGVIK, M.; BORRIES, B. Youth and History: a comparative european survey on historical and political attitudes among adolescents. v. A and B, Hamburg: Korber Foundation, 1997.

ASHBY, R; LEE, P. Children's concepts of empathy and understanding in history. In: PORTAL. C (Ed.). The History Curriculum for Teacher. Londres: The Falmer Press, 1987.

BARCA, I. Educação Histórica: uma nova área de investigação? In: ENCONTRO NACIONAL DE PESQUISADORES DE ENSINO DE HISTÓRIA, 6. 2005, Londrina. VI Encontro Nacional de Pesquisadores de Ensino de História. Londrina: Atrito Art, 2005, p. 15-25.

- Marcos de consciência histórica de jovens portugueses. Currículo sem fronteiras, v. 7, n. 1, p. 115-126, jan./jun., 2007.

Educação Histórica: pesquisar o terreno, favorecer a mudança. SCHMIDT, M. A.; BARCA, I. (Orgs.) Aprender História: perspectivas da educação histórica. Ijuí: Ed. Unijuí, 2009.

COSTA, A. L.; OLIVEIRA, M. M. D. O ensino de história como objeto de pesquisa no Brasil: no aniversário de 50 anos de uma área de pesquisa, notícias do que virá. Saeculom - Revista de História, João Pessoa, n. 16, p. 147-160, jan./jun. 2007.

DICKINSON, A; LEE, P. Understanding and research. In: DICKINSON, A; LEE, P. (Eds). History teaching and historical understanding. Londres: Heinemann, 1978.

Making sense history. In: DICKINSON, A; LEE, P; ROGERS, P. (Eds.) Learning history. Londres: Heinemann, 1984.

EVANGELISTA, O.; TRICHES, J. Ensino de história, Didática da História, Educação histórica: alguns dados de pesquisa (2000-2005). Educar em revista. Curitiba: Ed. UFPR, Especial, p. 33-55, 2006.

FONSECA, S. G. Caminhos da história ensinada. 3 ed. Campinas-SP: Papirus, 1995.

JUNG, H.; STAHER, G. Didáctica de la história y enseñanza de la historia em la Alemania unificada. In: Revista Conciencia Social. Madrid, n.2, p. 133-148, 1998.

LAVILLE, C. La recherche em éducation historique: mise en perspective et orientations actuelles. Notes pour la communication. Texto apresentado em seminário realizado no PPGE-PUC/SP, 1999. 
LEE, P. Progressão da compreensão dos alunos em história. In: BARCA, I. (Org.) Perspectivas em educação histórica. Actas das Primeiras Jornadas Internacionais de Educação Histórica. Braga: Centro de Estudos em Educação e Psicologia, Universidade do Minho, 2001. p.13-27.

Em direção a um conceito de literacia histórica. Educar em revista. Curitiba, Especial, p. 131-150, 2006.

MEDEIROS, D. H. de. A formação da consciência histórica como objetivo do ensino de história no ensino médio: o lugar do material didático. Curitiba, 2005. 194f. Tese (Doutorado em Educação) - Universidade Federal do Paraná.

PAIS, J. M. A consciência histórica e identidade: os jovens portugueses num contexto europeu. Oeiras: Celta: 1999.

RÜSEN, J. El desarrollo de la competencia narrativa en el aprendizaje histórico: una hipótesis ontogenética relativa a la conciencia moral. Trad. Silvia Finocchio. Propuesta Educativa, Argentina, n 7. out. 1992.

Conscientização histórica frente à pós-modernidade: a história na era da "nova transparência". Revista História, questões e debates, Curitiba, Departamento de História, UFPR, Ano 12, n. 20-21, 1997.

$\mathrm{UnB}, 2001$.

Razão Histórica: teoria da história: fundamentos da ciência histórica. Brasília:

SCHMIDT, M. A. Jovens brasileiros e europeus: identidade, cultura e ensino de história (1998-2000). Revista Perspectiva. Florianópolis, v. 20, n. Especial, p. 183-208, jul./dez. 2002.

Itinerários de pesquisa em ensino de história. In: ENCONTRO NACIONAL DE PESQUISADORES DE ENSINO DE HISTÓRIA, 6. 2005, Londrina. VI Encontro Nacional de Pesquisadores de Ensino de História. Londrina: Atrito Art, 2005. p. 113121.

SCHMIDT, M. A.; GARCIA, T. M. F. B. Consciência Histórica e crítica em aulas de história. Fortaleza: Secretária da Cultura do Estado do Ceará/Museus do Ceará, 2006a. (Cadernos Paulo Freire - v. 4)

Pesquisas em educação histórica: algumas experiências. Educar em revista. Curitiba, Especial, p. 11-31, 2006b.

TUTIAUX-GUILLON, N; MOUSSEAU, M. J. Les jeunes et l' histoire, valeurs, conscience historique. Paris: INRP, 1998.

Notas:

\footnotetext{
${ }^{1}$ Professor Adjunto do PPG-ED - Mestrado em Educação da Universidade Tuiuti do Paraná; pesquisador do Laboratório de Pesquisa em Educação Histórica do PPGE/UFPR; geysog@ gmail.com

2 Todos estes autores foram referenciados por: BARCA, Isabel. Marcos de consciência histórica de jovens portugueses. Currículo sem fronteiras, Lisboa, v. 7, n. 1, p. 115-126, jan./jun., 2007.

${ }^{3}$ Idem.
} 